\title{
Association of Neurotensin Binding Sites with Sensory and Visceromotor Components of the Vagus Nerve
}

\author{
J. P. Kessler and A. Beaudet \\ Montreal Neurological Institute, McGill University, Montreal, Quebec H3A 2B4, Canada
}

\begin{abstract}
Specific neurotensin (NT) binding sites were recently shown to be highly concentrated in the nucleus of the solitary tract (NTS), which receives primary vagal afferents, and in the dorsal motor nucleus of the vagus (DMN), which contains the cell bodies of origin of vagal preganglionic neurons. To investigate the relationship of these binding sites with sensory and visceromotor components of the vagus nerve, they were labeled here in vitro, using monoiodo[Tyr $\mathbf{r}^{3}$ ]neurotensin (125I-NT) and visualized by light microscopic radioautography in the dorsomedial medulla of both intact and unilaterally vagotomized rats, in the nodose ganglia of intact animals, and in ligated vagus nerves. Unilateral vagotomy performed above the nodose ganglion resulted in a significant ipsilateral decrease in ${ }^{125}$-NT binding within both the NTS and the DMN, suggesting that NT binding sites were associated with both primary afferent fibers and preganglionic nerve cell bodies. The selective radioautographic labeling of a subpopulation (approximately $15 \%$ ) of neuronal perikarya in the nodose ganglion confirmed that a proportion of vagal afferent neurons contained NT binding sites. Following vagus nerve ligation, a pile up of radiolabeled NT binding sites was observed on both sides of the nerve crush, indicating that NT receptor components were transported both anterogradely and retrogradely along fibers of the vagus nerve. We conclude that NT receptors are synthesized and transported within a subpopulation of afferent and efferent components of the vagus nerve and that NT may therefore act presynaptically upon vagal axon terminals in both central and peripheral nervous systems.
\end{abstract}

Neurotensin (NT) is a tridecapeptide widely distributed throughout the CNS (Carraway and Leeman, 1976; Uhl and Snyder, 1976; Kobayashi et al., 1977), where it is believed to act as a neurotransmitter/neuromodulator (for review, see Kitabgi et al., 1985). Anatomical and physiological studies in the

Received July 7, 1987; revised July 5, 1988; accepted July 12, 1988.

This work was supported by Grant MT-7366 and a Scientist Award to A. B. from the Medical Research Council of Canada and by a training grant to J.P.K. from External Affairs, Canada. We are grateful to P. Kitahgi and J. P. Vincent (Nice, France) for their generous provision of monoiodinated neurotensin. We thank K. Leonard for technical assistance, C. Hodge for photographic work, and B. Lindsay for typing the manuscript. We also thank Dr. B. E. Jones for reviewing the manuscript.

Correspondence should be addressed to Dr. A. Beaudet, Neuroanatomy Laboratory, Montreal Neurological Institute, 3801 University Street, Montreal, Quebec H3A 2B4, Canada.

a Present address: Département de Physiologie et Neurophysiologie, Faculté des Sciences et Techniques Saint-Jérome, Université d'Aix-Marseille III, Rue HenriPoincaré, 13397 Marseille Cedex 13, France.

Copyright $(61989$ Society for Neuroscience $0270-6474 / 89 / 020466-07 \$ 02.00 / 0$ rat suggest that NT might be involved in the regulation of autonomic functions mediated by the vagus nerve. NT-containing perikarya and/or axonal processes have been identified by immunohistochemistry within both sensory and visceromotor components of the vagus nerve, namely, in the nucleus of the solitary tract (NTS), which receives vagal visceral afferents, and in the dorsal motor nucleus of the vagus (DMN), which contains vagal preganglionic parasympathetic neurons (Uhl et al., 1979; Jennes et al., 1982; Higgins et al., 1984; Hökfelt et al., 1984; Yamazoe et al., 1984). High concentrations of specific highaffinity NT binding sites, with pharmacological characteristics of functional receptors (Kitabgi et al., 1985), have been demonstrated within the same 2 nuclei by means of light microscopic radioautography (Young and Kuhar, 1981; Quirion et al., 1982; Kessler et al., 1987). These receptors are likely to be involved in the mediation of the apneustic breathing response elicited by microinjection of NT into the NTS (Morin-Surun et al., 1986). They could also mediate some of the autonomic effects reported after intraventricular administration of NT, such as hypotension (Quirion et al., 1981; Rioux et al., 1981) and inhibition of gastric acid secretion (Osumi et al., 1978), which may both result from a modification of vagal parasympathetic activity.

The present study was performed in order to determine whether NT receptors present within the NTS and the DMN are directly localized on vagus nerve components. NT binding sites were labeled by radioautography, using either film or conventional emulsion coating procedure, and their distribution was examined in the NTS, the DMN, the vagus nerve, and the nodose ganglion before and/or after vagotomy or ligation of the vagus nerve. A preliminary report of the present results has appeared previously (Kessler and Beaudet, 1986).

\section{Materials and Methods}

Experiments were carried out in adult male Sprague-Dawley rats (225$250 \mathrm{gm})$ pretreated with atropine $(10 \mathrm{mg} / \mathrm{kg}$, i.p.) and anesthetized with pentobarbital $(6 \mathrm{mg} / \mathrm{kg}$, i.p.).

In a first group of animals, the ventral surface of the neck was incised and the cervical portion of the left vagus nerve exposed. The nerve was then sectioned just above the nodose ganglion (Fig. 1). The latter was identified as the enlargement interposed between the branching of the superior laryngeal nerve and the penetration of the vagus nerve into the skull through the jugular foramen. Sham animals were operated in parallel, whereby the left vagus and nodose ganglion were exposed but left intact. All animals were sacrificed $7 \mathrm{~d}$ later by decapitation. The brains were rapidly removed and frozen by immersion in liquid isopentane at $-40^{\circ} \mathrm{C}$ for $20 \mathrm{sec}$ and stored at $-80^{\circ} \mathrm{C}$ until used.

In a second group of rats, unilateral vagus nerve ligations were performed using a surgical approach similar to that described above. Both vagus nerves were exposed, and a ligature was placed on either the right or the left nerve, $5 \mathrm{~mm}$ below the nodose ganglion (Fig. 1). After a recovery period of $24 \mathrm{hr}$, both vagus nerves were removed under pen- 


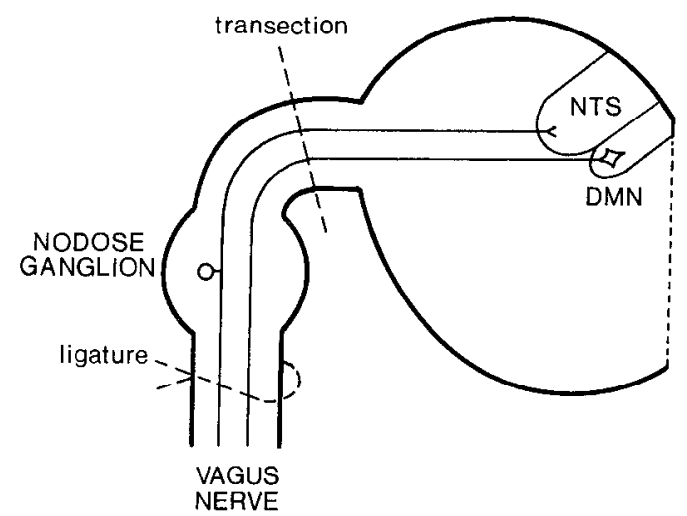

Figure 1. Schematic representation of central vagal pathways. In a first series of animals, the vagus nerve was transected immediately above the nodose ganglion interrupting both afferent fibers, which originate from the nodose, and efferent preganglionic fibers, which arise from the DMN. In a second group of animals, the vagus nerve was ligated $5 \mathrm{~mm}$ below the ganglion, again interrupting axonal flow in both afferent and efferent fibers. NTS, nucleus of the solitary tract; $D M N$, dorsal motor nucleus of the vagus nerve.

tobarbital anesthesia, frozen in isopentane at $-40^{\circ} \mathrm{C}$, and stored at $-80^{\circ} \mathrm{C}$ until used.

Finally, in a last group of rats, right and/or left nodose ganglia $(n=$ 5) were removed, frozen, and stored as described above.

The brain stems of vagotomized and sham-operated animals, the vagus nerves of unilaterally ligated animals, and the nodose ganglia from intact animals were all cut $\left(5-20 \mu \mathrm{m}\right.$ thick) on a cryostat at $-20^{\circ} \mathrm{C}$, mounted onto $2 \%$ gelatin-coated slides, and stored at $-20^{\circ} \mathrm{C}$ for at least $24 \mathrm{hr}$ before use.

For radioautographic labeling of NT binding sites, the sections were incubated with $0.1 \mathrm{nM}$ monoiodo [Tyr'] neurotensin ( ${ }^{225} \mathrm{I}-\mathrm{NT} ; 2000$ $\mathrm{Ci} / \mathrm{mmol}$ ) in $50 \mathrm{~mm}$ Tris- $\mathrm{HCl}$ buffer, pH 7.6 , containing $5 \mathrm{mM} \mathrm{MgCl}_{2}$, $0.2 \% \mathrm{BSA}, 2 \times 10^{-5} \mathrm{M}$ Bacitracin and $0.25 \mathrm{M}$ sucrose at $4^{\circ} \mathrm{C}$ as previously described (Moyse et al., 1987). ${ }^{125}$ I-NT was kindly provided by Drs. P. Kitabgi and J. P. Vincent (Nice, France). Additional sections were incubated in the presence of $0.5 \mu \mathrm{M}$ native NT for determination of nonspecitic binding. After incubation, the sections were washed for $8 \mathrm{~min}$ at $4^{\circ} \mathrm{C}$ in 4 consecutive baths of $50 \mathrm{~mm}$ Tris-sucrose, $\mathrm{pH} 7.6$, and processed for radioautography using either film or liquid emulsion coating techniques.

Film radioautographs were produced by apposition of labeled sections to tritium-sensitive Ultrofilm (LKB, Sweden) in Kodak X-ray cassettes. Following $6 \mathrm{~d}$ of exposure, the films were developed for $3 \mathrm{~min}$ in Kodak GBX, rinsed in water, and fixed with Kodak fixer.

For light microscopic radioautography, labeled sections werc fixed by immersion in a $4 \%$ glutaraldehyde solution in $50 \mathrm{mM} \mathrm{PO}_{4}$ buffer at $4^{\circ} \mathrm{C}$ for $30 \mathrm{~min}$. The sections were then dehydrated in graded ethanols, defatted in xylene, and rehydrated through an inverse series of ethanols as previously described (Hamel and Beaudet, 1984). The slides were coated by dipping in Kodak NTB-2 emulsion diluted 1:1 with distilled water. After 6 weeks of exposure at $4^{\circ} \mathrm{C}$, the radioautographs were developed in Dektol (Kodak), fixed in Ektaflo (Kodak), and stained with cresyl violet.

The effects of vagotomy on NT binding within the DMN and the NTS were assessed by optical density measurements in film radioautographs. Measurements were performed by means of a Bioquant computerized image-analyzing system coupled to a Leitz Orthoplan microscope. The range in which densitometric measurements were made was confirmed to be linear using iodinated standards prepared from "brain paste" homogeneously labeled with ${ }^{125} I-\delta$-titus toxin (Rostene and Mourre, 1985). Labeling over the DMN was assessed in serial sections taken at $150 \mu \mathrm{m}$ intervals across the entire rostrocaudal extent of the nucleus. Labeling densities over caudal and rostral NTS were measured respectively in sections taken from the obex (i.e., rostral to the commissural segment of the nucleus; see Hamilton and Norgren, 1984) to the rostral border of the area postrema and from the rostral border of the area postrema to the level at which the medial border of the NTS joins the lateral wall of the fourth ventricle. Here again, sections were separated by $150 \mu \mathrm{m}$ intervals. Statistical comparison between data from vagotomized and sham-lesioned animals was performed using the Student $t$ test.

\section{Results \\ Distribution of NT binding sites within the dorsal vagal complex}

Both film and liquid emulsion processed radioautographs from sections of the rat medulla incubated with ${ }^{125}$ I-NT show specific labeling in the DMN and NTS (Fig. 2, $a, b, d, e$ ). Within the $\mathrm{DMN}$, the labeling is uniformly intense throughout the nucleus. Within the NTS, the labeling pattern varies markedly along the rostrocaudal axis. In the rostralmost portion of the nucleus, the labeling is intense along the medial edge, within the region previously shown to contain vagal and glossopharyngeal efferent cell bodies (Contreras et al., 1980; Kalia and Sullivan, 1982) and dense to moderate laterally. Between the caudal pole of the medial vestibular nucleus and the rostral border of the area postrema, the labeling is dense within the medial subdivision of the NTS and moderate laterally (Fig. 2e). At the level of the area postrema, the labeling is moderate and mainly confined to the dorsal edge of the NTS, with extensions around the solitary tract and within the interstitial nucleus (Fig. 2b). Caudal to the obex, the labeling is also moderate and restricted to the commissural nucleus. At high magnification of liquid emulsion processed material, silver grains in the DMN appear to be prefercntially accumulated over nerve cell bodics but are also cvident over the intervening neuropil (Fig. $3 b$ ). Within the NTS the radioactivity is more or less uniformly distributed over perikarya and neuropil.

\section{Effects of vagus nerve transection}

Seven days after unilateral supranodose vagotomy, perikarya within the ipsilateral DMN exhibit increased cytoplasmic basophilia (Fig. 3a). A concomitant decrease in NT binding is apparent within the DMN ipsilateral to the lesion in both film and liquid emulsion processed material (Fig. 2, $c, f$ ). This decrease is evident through the full mediolateral and rostrocaudal extent of the nucleus. In liquid emulsion coated sections, only rare labeled nerve cell bodies are still visible on the ipsilateral side (Fig. 3c). A decrease in silver grain density is also apparent over the neuropil (compare $b$ and $c$ in Fig. 3). Quantitative analyses of film radioautograms confirm that labeling densities within the ipsilateral DMN are significantly reduced (by approximately $68 \%$ ) compared with the contralateral side (Fig. 4). Ipsilateral optical density values are also significantly lower in vagotomized than in sham-lesioned animals (Fig. 4). No significant difference in labeling density is noted on the unlesioned side between vagotomized and sham-operated animals or between right and left sides in sham-lesioned animals (Fig. 3).

Unilateral vagotomy also results in a slight decrease in ${ }^{125} \mathrm{I}$ NT labeling within the ipsilateral NTS, apparent in both film and emulsion coated material (Fig. $2 c, f$ ). This decrease affects both rostral and caudal portions of the nucleus (Fig. 5) and shows no consistent predilection for any given subdivision, even though in certain planes of section the medial NTS appears somewhat more affected than lateral or interstitial segments (Fig. 2c). Overall binding densities are reduced by $24 \%$ rostrally and $21 \%$ caudally compared with the contralateral side and are significantly different from those recorded both contralaterally and in sham-lesioned rats (Fig. 5). In contrast, there is no significant difference between unlesioned sides in vagotomized and sham- 

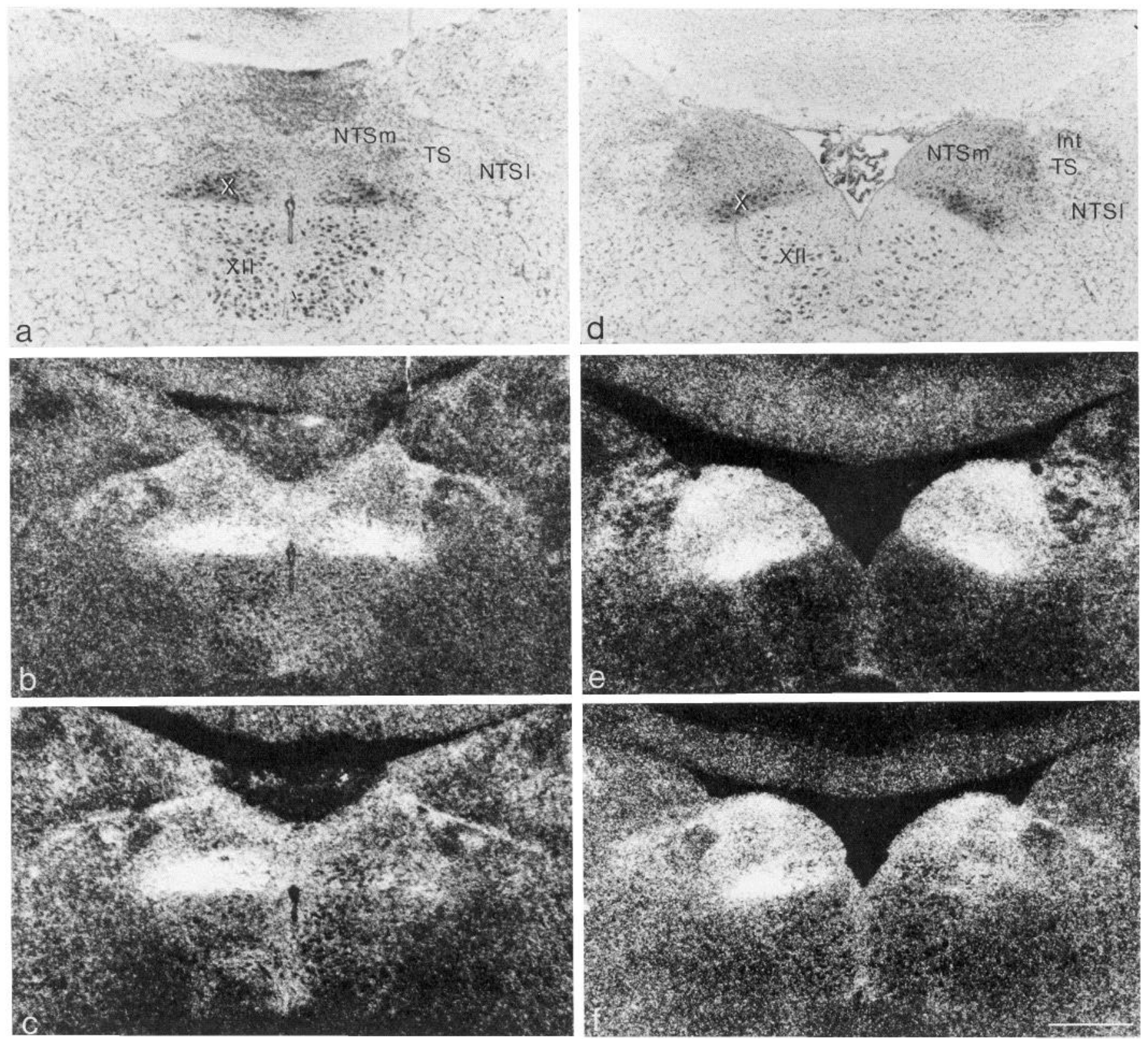

Figure 2. Radioautographic distribution of ${ }^{125}$ I-NT labeled binding sites in the caudal $(a-c)$ and rostral $(d-f)$ vagal complex of sham $(a$ and $b$, $d$ and $e$ ) and unilaterally vagotomized $(c, f)$ rats. Liquid emulsion processed material. Bright-field $(a, d)$ and dark-field $(b, e)$ micrographs from the same sections, and dark-field micrographs $(c, f)$ from sections taken at the same 2 rostrocaudal levels in vagotomized animals. A slight decrease in NT binding is noted over the NTS and a marked decrease over the DMN, ipsilateral to the transection. TS, solitary tract; NTSm, medial nucleus of the solitary tract; NTSl, lateral nucleus of the solitary tract; Int, interstitial nucleus of the solitary tract; $X$, dorsal motor nucleus of the vagus; $X I I$, hypoglossal nucleus. NTS cytoarchitectonic divisions are after Hamilton and Norgren (1984). Scale bar, $400 \mu \mathrm{m}$.

lesioned animals or between right and left sides in sham-lesioned animals (Fig. 5).

\section{${ }^{125} I-N T$ binding within the nodose ganglion}

Following incubation of sections from nodose ganglia with ${ }^{125} \mathrm{I}$ NT, $15 \%$ of ganglion cells exhibit dense radioautographic labeling. Labeled perikarya are more or less uniformly scattered throughout the ganglion (Fig. 6, $a, b$ ). At high magnification, silver grains are found to overlie the entire perikaryal surface but systematically spare cross-sectioned nuclei (Fig. $6, b, c$ ). In rare instances, the label can be followed for a short distance over proximal axons (Fig. $6 a$ ).

\section{Effects of vagus nerve ligation}

Sections from ligated vagus nerves exhibit intense ${ }^{125}$ I-NT labeling on both sides of the ligature, indicating a pileup of NT binding sites (Fig. 7). This pileup is more intense on the proximal (central) than on the distal (peripheral) side. By contrast, only background levels of radioactivity are detected within unligated vagus nerves. The superior laryngeal nerve, also included in the ligation, shows no or only a weak pileup of labeled binding sites.

\section{Discussion}

The present data indicate that unilateral supranodose vagotomy reduces NT binding within the ipsilateral DMN and NTS. The 


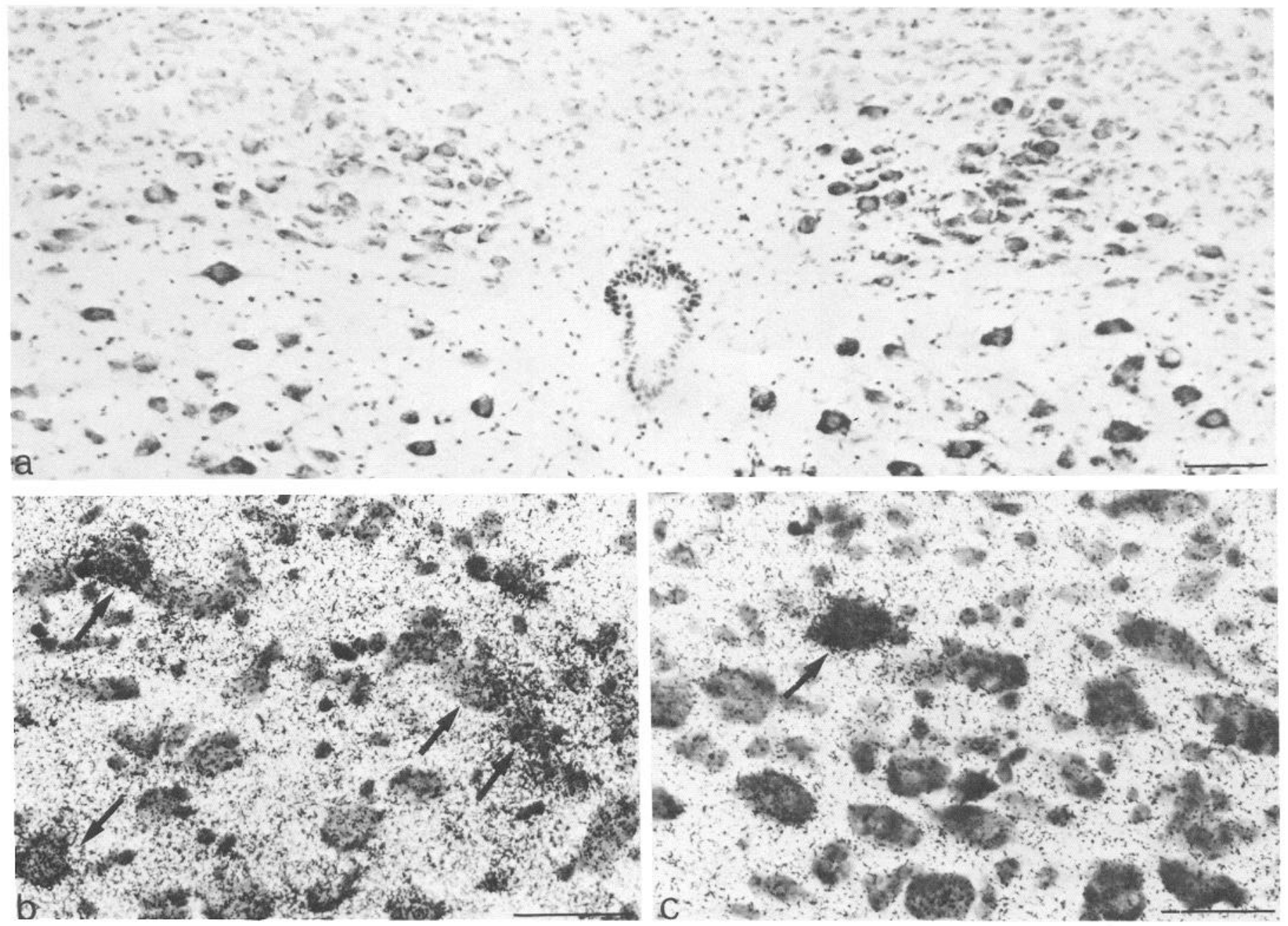

Figure 3. a, Cresyl violet-stained sections of the dorsomedial medulla exemplifying vagotomy-induced histological changes within the DMN. Most perikarya exhibit increased cytoplasmic basophilia on the side ipsilateral to the lesion (right). Scale bar, $100 \mu \mathrm{m} . b$ and $c$, Light microscopic radioautographs from sections of the DMN incubated with ${ }^{125}$ I-neurotensin before $(b)$ and after $(c)$ ipsilateral vagotomy. In sham-operated animals $(b)$, the labeling is dense over both perikarya (arrows) and neuropil. Following vagotomy $(c)$, only a few nerve cell bodies are still labeled (arrows) and labeling densities are decreased over the neuropil. Scale bars, $50 \mu \mathrm{m}$.

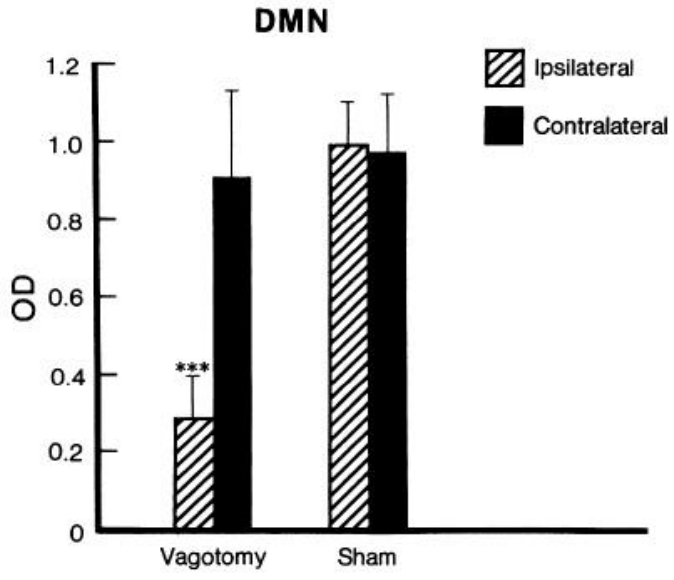

Figure 4. Effect of unilateral vagotomy on ${ }^{125} \mathrm{I}-\mathrm{NT}$ binding within the DMN. Densitometric measurements performed on film radioautographs from vagotomized $(n=8)$ and sham-lesioned $(n=6)$ animals. Data are expressed in arbitrary optical density units (means $\pm \mathrm{SD} ;{ }^{* * *}$, significantly different from both sham and contralateral side with $p<$ 0.001).
Caudal NTS
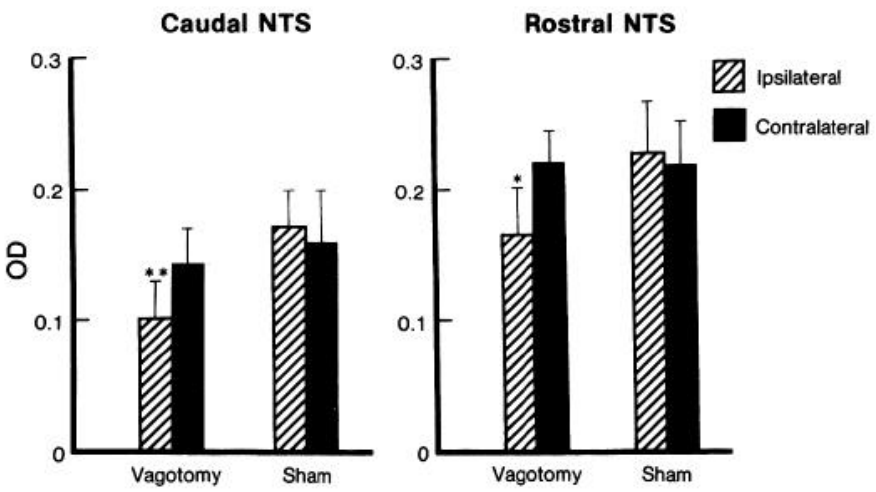

Figure 5. Effect of unilateral vagotomy on ${ }^{125} \mathrm{I}$-neurotensin binding within the NTS. Densitometric measurements performed on film radioautographs from vagotomized $(n=8)$ and sham-lesioned $(n=6)$ animals. Data are expressed in arbitrary optical density units (means $\pm \mathrm{SD} ;{ }^{* *}$, significantly different from sham-lesioned group with $p<$ 0.01 and from contralateral side with $p<0.05 ; *$, significantly different from sham-lesioned group with $p<0.025$ and from contralateral side with $p<0.01$ ). 

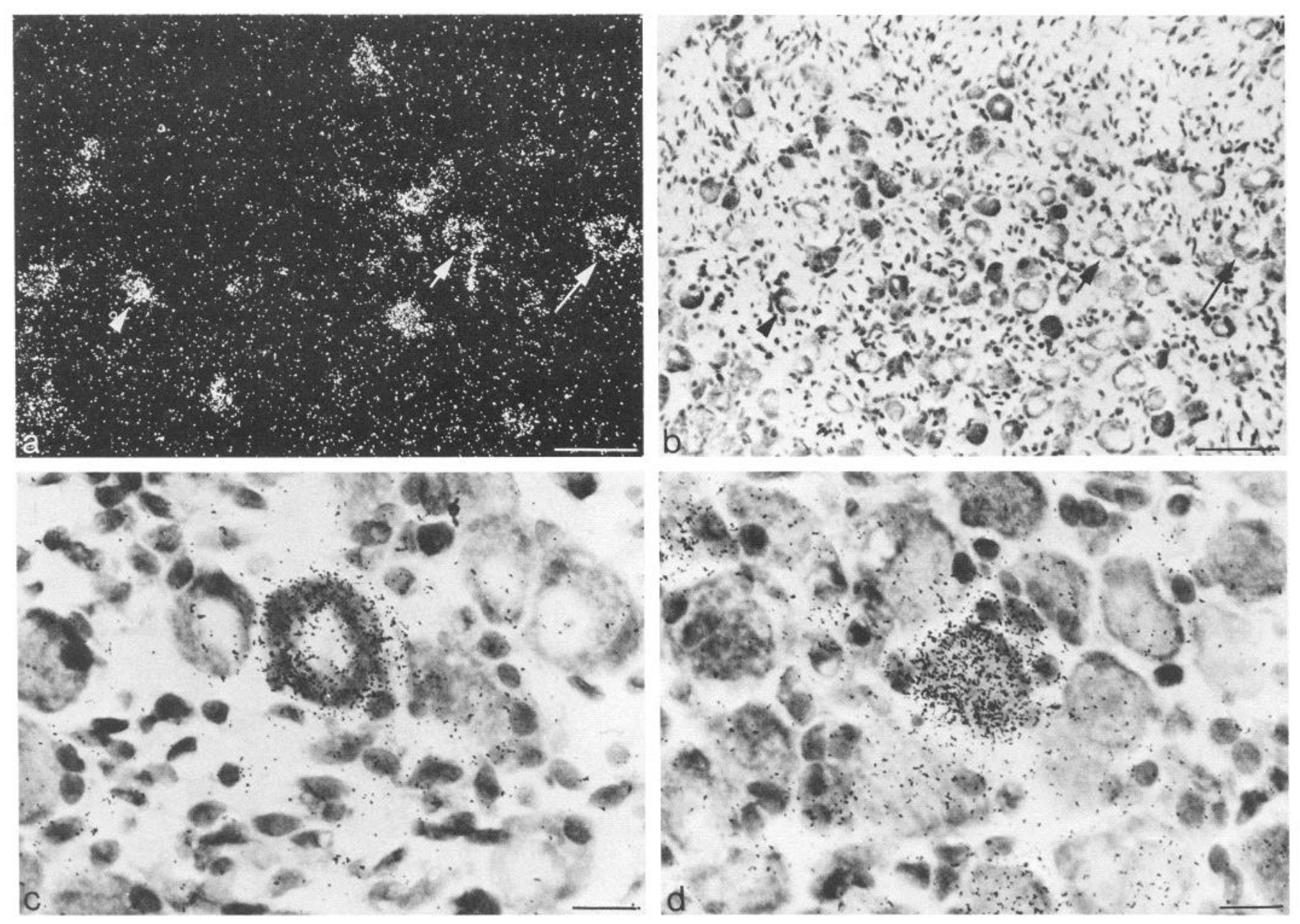

Figure 6. Light microscopic radioautographic distribution of bound ${ }^{125}$ I-NT in the nodose ganglion. $a$ and $b$, Same field is seen here at low magnification in dark-field $(a)$ and bright-field $(b)$. Note that the labeling involves only a subpopulation (approximately $15 \%$ ) of ganglion cells (arrows). In rare instances, the label can be followed for a short distance over proximal axons (short arrow). Scale bars, $100 \mu \mathrm{m}$. $c$ and $d$, At high magnification, the label is apparent throughout the cytoplasm but clearly spares cross-sectioned nuclei $(c)$. Scale bars, $20 \mu \mathrm{m}$.

reduction observed in the DMN is likely to result from degenerative changes occurring within axotomized vagal preganglionic efferent neurons. Indeed, as previously reported, most DMN perikarya ipsilateral to the vagal transection exhibit increased cytoplasmic basophilia, indicating that they are the site of intense axotomy-induced metabolic perturbation (Aldskogius et al., 1980). Such perturbation presumably translates into a decrease in the synthesis of NT binding sites, reflected here by a loss of perikaryal labeling. The few labeled cells remaining on the lesioned side probably correspond to vagal efferent neurons comparatively less vulnerable to vagotomy (Laiwand et al., 1987) or projecting through the contralateral vagus nerve (Mitchell and Warwick, 1955; Contreras et al., 1980; Karim and Leong, 1980). The decrease in ${ }^{125}$ I-NT binding recorded within the DMN could also be due, directly or transsynaptically, to the degeneration of primary vagal afferents, but this possibility appears less likely since afferent projections to the DMN are sparse and confined to specific segments of the nucleus (Contreras et al., 1982; Kalia and Sullivan, 1982; Neuhuber and Sandoz, 1986).

In contrast, the decrease in NT binding recorded in the NTS is likely to result from the degeneration of vagal afferent fibers. The fact that it is confined to the ipsilateral side conforms with this interpretation since the vast majority of vagal afferent fibers are known to project to the ipsilateral NTS (Contreras et al., 1982; Kalia and Sullivan, 1982; Leslie et al., 1982; Hamilton and Norgren, 1984). Both the presence of labeled cell bodies in the nodose ganglion and the pileup of radioactivity observed in the vagus nerve $24 \mathrm{hr}$ after ligation support the view that the lost binding sites were originally associated with primary afferent fibers and/or terminals, the former by indicating that NT binding sites are actually contained within vagal sensory neurons and the latter by demonstrating that NT binding sites are being transported within vagal afferent fibers. However, the possibility that the drop in NT binding may in part be due to secondary transsynaptic degeneration (or down-regulation) of primary afferent targets within the NTS or to degeneration of distal DMN dendrites arborizing within the NTS (Shapiro and Miselis, 1985) cannot be formally excluded.

The relatively modest decrease in NT binding observed within the NTS is congruent with the small proportion of ganglion cells found here to bind ${ }^{125}$ I-NT in the nodose. This subpopulation does not appear to preferentially arborize in either the rostral or caudal part of the NTS since following vagotomy the decrease in NT binding is comparable in both segments of the nucleus. It would be of interest to determine whether the labeled cells correspond to a functionally or chemically distinct subpopulation of primary afferent neurons. Whatever the case, the 


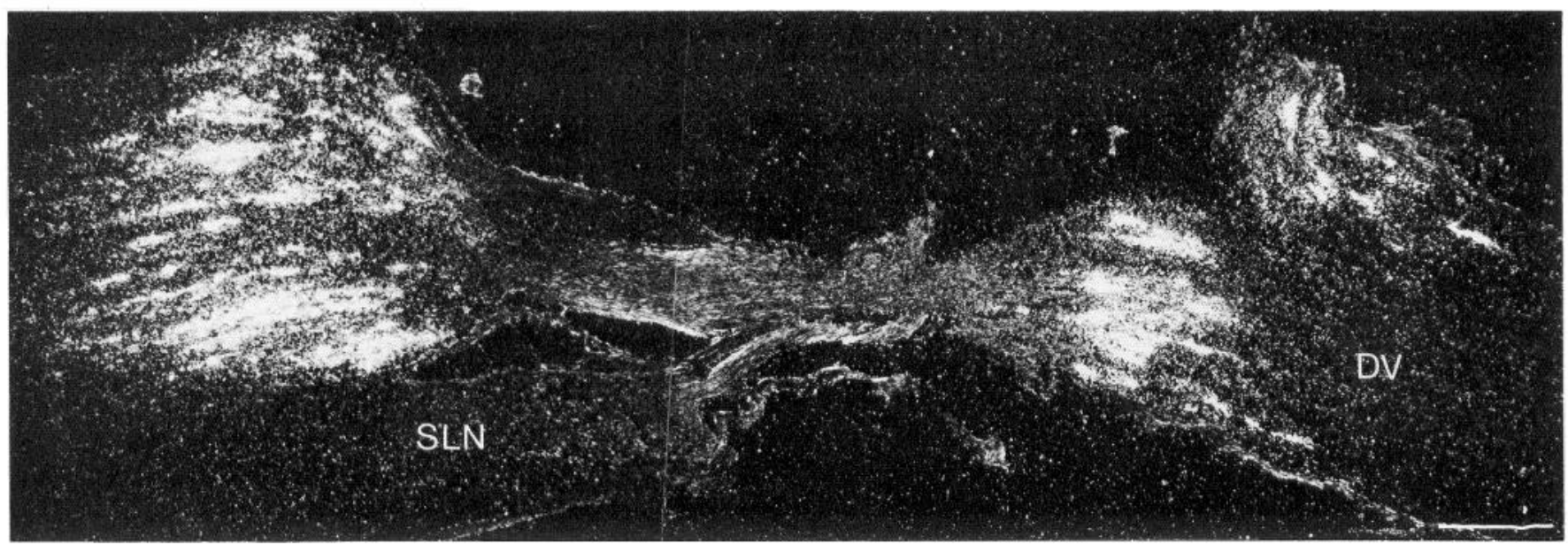

Figure 7. ${ }^{125}$ I-NT binding in ligated vagus nerve. Dark-field photomicrograph from an emulsion-dipped section. Radioautographic labeling, indicative of a pileup of labeled binding sites, is present on both sides of the nerve crush. Note the absence of labeling over the superior laryngeal nerve $(S L N)$, which was also included in the ligature. $D V$, vagus nerve distal to the ligature. Scale bar, $200 \mu \mathrm{m}$.

presence of binding sites on central afferent terminals implies that NT may presynaptically modulate visceral inputs within the NTS.

The absence of silver grains over cross-sectioned nuclear profiles of labeled ganglion cells suggests that most of the binding sites visualized in the nodose are intraperikaryal. Such intracellular binding sites presumably correspond to receptor components that are either newly synthesized or are on their way to degradation and/or reprocessing. Whether some of the binding sites labeled in the nodose are membrane bound and may therefore correspond to functional receptors remains to be determined. Interestingly, receptors pharmacologically responsive to other neurotransmitters, especially to ACh and 5-HT, have been shown to be present on nodose ganglion cells (Higashi, 1980; Higashi and Nishi, 1982). The absence of immunodetectable NT within vagal neurons (Lundberg et al., 1982), however, raises questions about the role that membrane-bound NT receptors might be playing within the ganglion.

The fact that a pileup of radioactivity is observed in the vagus nerve on the ganglion side of a ligature distal to the nodose (Fig. 1) indicates that NT binding sites may be anterogradely transported not only in central branches, as corroborated by the results of vagotomy experiments, but also in peripheral branches of vagal sensory neurons. The functional significance of NT binding sites thus transported within peripheral branches of vagal sensory neurons is unclear. As previously suggested for angiotensin II (Diz et al., 1986), NT may modify the generation and/or propagation of action potentials at the level of peripheral sensory endings.

It is unlikely that the small population of ganglion cells labeled in the nodose alone accounts for the massive pileup of radioactivity observed in the vagus nerve proximal to the ligation. Visceral efferent fibers, originating from cell bodies labeled within the DMN, are probably also involved. Branchiomeric fibers are less likely to be implicated in view of the virtual absence of ${ }^{125} \mathrm{I}-\mathrm{NT}$ binding detected at the level of their cell bodies of origin in the nucleus ambiguus (Kessler et al., 1987). Binding sites anterogradely transported within visceral efferent neurons could serve as a substrate for a presynaptic action of systemic NT on vagal axon terminals within vagal target organs. It is of interest to recall in this context that NT has been shown to induce the release of ACh in the guinea pig ileum (Kitabgi and Freychet, 1979).

The occurrence of a radioactive pileup on the distal as well as on the proximal side of the ligation indicates that the transport of NT binding sites is bidirectional in the vagus nerve. Within the same nerve, ACh (Zarbin et al., 1982) and opioid (Young et al., 1980; Laduron and Janssen, 1985) receptors have similarly been shown to move in both retrograde and anterograde directions. By contrast, cholecystokinin binding sites were found to be transported only anterogradely (Zarbin et al., 1981). The present results do not allow us to determine whether ${ }^{125} \mathrm{I}-\mathrm{NT}$ labeled binding sites are retrogradely transported in sensory or visceromotor axons or in both. Here again, however, the size of the pileup suggests that both fiber types are involved. Retrograde transport of NT receptor components are presumably required for subsequent degradation and reprocessing of the receptors, since most proteolytic enzymes are found in cell bodies. Alternatively, retrograde transport may represent a step in the receptor-mediated sequence of events that ensures internalization and translocation of the bound ligand to an intracellular site of action. A similar hypothesis has been proposed to account for the retrograde transport of bound opiate peptides within the vagal sensory fibers (Laduron and Janssen, 1985). Confirmation of this hypothesis would imply that peripherally released NT may act centrally on CNS neurons.

\section{References}

Aldskogius, H., K. D. Barron, and R. Regal (1980) Axon reaction in dorsal motor vagal and hypoglossal neurons of the adult rat. Light microscopy and RNA-cytochemistry. J. Comp. Neurol. 193: 165177.

Carraway, R., and S. E. Leeman (1976) Characterization of radioimmunoassayable neurotensin in the rat. Its differential distribution in the central nervous system, small intestine and stomach. J. Biol. Chem. 251: 7045-7052.

Contreras, R. J., M. M. Gomez, and R. Norgren (1980) Central origin of cranial nerve parasympathetic neurons in the rat. J. Comp. Neurol. 190: 373-394.

Contreras, R. J., R. M. Beckstead, and R. Norgren (1982) The central projections of the trigeminal, facial, glossopharyngeal and vagus nerves: An autoradiographic study in the rat. J. Autonom. Nerv. Syst. 6: 303322.

Diz, D. I., K. L. Barnes, and C. M. Ferrario (1986) Contribution of 
the vagus nerve to angiotensin II binding sites in the canine medulla. Brain Res. Bull. 17: 497-505.

Hamel, E., and A. Beaudet (1984) Localization of opioid binding sites in rat brain by electron microscopic radioautography. J. Electron Microsc. Tech. 1: 317-329.

Hamilton, R. B., and R. Norgren (1984) Central projections of gustatory nerves in the rat. J. Comp. Neurol. 222: 560-570.

Higashi, H. (1980) Chemoreceptors for serotonin, acetylcholine, bradykinin, and histamine are present on the soma of unmyelinated visceral afferents in the rabbit nodose ganglion. Soc. Neurosci. Abstr. 6: 356.

Higashi, H., and S. Nishi (1982) 5-Hydroxytryptamine receptors of visceral primary afferent neurons on rabbit nodose ganglia. J. Physiol. (Lond.) 323: 543-567.

Higgins, G. A., G. E. Hoffman, S. Wray, and J. S. Schwaber (1984) Distribution of neurotensin-immunoreactivity within baroreceptive portions of the nucleus tractus solitarius and the dorsal vagal nucleus of the rat. J. Comp. Neurol. 226: 155-164.

Hökfelt, T., B. J. Everitt, E. Theodorsson-Norheim, and M. Goldstein (1984) Occurrence of neurotensin-like immunoreactivity in subpopulations of hypothalamic, mesencephalic and medullary catecholamine neurons. J. Comp. Neurol. 222: 543-559.

Jennes, L., W. E. Stumpf, and P. W. Kalivas (1982) Neurotensin: Topographical distribution in rat brain by immunohistochemistry. J. Comp. Neurol. 210: 211-224.

Kalia, M., and J. M. Sullivan (1982) Brainstem projections of sensory and motor components of the vagus nerve in the rat. J. Comp. Neurol. 211: 248-264.

Karim, M. A., and S. K. Leong (1980) Neurons of origin of ccrvical vagus nerves in the rat and monkey. Brain Res. 186: 208-210.

Kessler, J. P., and A. Beaudet (1986) High affinity neurotensin binding to afferent and efferent components of the vagal complex. Neurosci. Abstr. 12: 811 .

Kessler, J. P., E. Moyse, P. Kitabgi, J. P. Vincent, and A. Beaudet (1987) Distribution of neurotensin binding sites in the caudal brainstem of the rat: A light microscopic radioautographic study. Neuroscience 23: 189-198.

Kitabgi, P., and P. Freychet (1979) Neurotensin contracts the guineapig longitudinal ileal smooth muscle by inducing acetylcholine release. Eur. J. Pharmacol. 56: 403-406.

Kitabgi, P., F. Checler, J. Mazella, and J. P. Vincent (1985) Pharmacology and biochemistry of neurotensin receptors. Rev. Basic Clin. Pharmacol. 5: 397-486.

Kobayashi, R. M., M. Brown, and W. Vale (1977) Regional distribution of neurotensin and somatostatin in the rat brain. Brain Res. 126: 584-588.

Laduron, P., and P. F. M. Janssen (1985) Retrograde axonal transport of receptor-bound opiate in the vagus and delayed accumulation in the nodose ganglion. Brain Res. 333: 389-392.

Laiwand, R., R. Werman, and Y. Yarom (1987) Time course and distribution of motoneuronal loss in the dorsal motor vagal nucleus of guinea pig after cervical vagotomy. J. Comp. Neurol. 256: 527537.

Leslie, R. A., D. G. Gwyn, and D. A. Hopkins (1982) The central distribution of the cervical vagus nerve and gastric afferent and efferent projections in the rat. Brain Res. Bull. $8: 37-43$.

Lundberg, J. M., A. Rokaeus, T. Hökfelt, S. Rosell, M. Brown, and M.
Goldstcin (1982) Ncurotensin-likc immunoreactivity in the preganglionic sympathetic nerves and in the adrenal medulla of the cat. Acta Physiol. Scand. 114: 153-155.

Mitchell, G. A. G., and R. Warwick (1955) The dorsal vagal nucleus. Acta Anat. 75: 371-395.

Morin-Surun, M. P., D. Marlot, J. P. Kessler, and M. Denavit-Saubié (1986) The excitation by neurotensin of nucleus tractus solitarius neurons induces apneustic breathing. Brain Res. 384: 106-113.

Moyse, E., W. Rostène, M. Vial, K. Leonard, J. Mazella, P. Kitabgi, J. P. Vincent, and A. Beaudet (1987) Distribution of neurotensin binding sites in rat brain: A light microscopic radioautographic study using monoiodo ${ }^{125} \mathrm{I}-\mathrm{Tyr}_{3}$-neurotensin. Neuroscience 22: 525-536.

Neuhuber, W. L., and P. A. Sandoz (1986) Vagal primary afferent terminals in the dorsal motor nucleus of the rat: Are they making monosynaptic contacts on preganglionic efferent neurons? Neurosci. Lett. 69: 126-130.

Osumi, Y., L. Nagasaka, H. Wang, and M. Fujiwara (1978) Inhibition of gastric acid secretion and mucosal blood flow induced by intraventricularly applied neurotensin in rats. Life Sci. 23: 2275-2280.

Quirion, R., F. Rioux, S. St-Pierre, F. Bélanger, F. B. Jolicoeur, and A. Barbeau (1981) Hypotensive effects of centrally and peripherally administered neurotensin and neurotensin derivatives in rats. Neuropeptide 1: 253-259.

Quirion, R., P. Gaudreau, S. St-Pierre, F. Rioux, and C. B. Pert (1982) Autoradiographic distribution of neurotensin receptors in rat brain: Visualization by tritium sensitive film. Peptides 3: 757-763.

Rioux, F., R. Quirion, S. St-Pierre, D. Regoli, F. Jolicoeur, F. Belanger, and A. Barbeau (1981) The hypotensive effective of centrally administercd ncurotensin in rats. Eur. J. Pharmacol. 69: 241-247.

Rostène, W., and C. Mourre (1985) Préparation de standards iodés pour la radioautographie quantitative in vitro à l'aide d'un film sensible au tritium. C. R. Acad. Sci. Paris 301: 245-250.

Shapiro, R. E., and R. R. Miselis (1985) The central organization of the vagus nerve innervating the stomach of the rat. J. Comp. Neurol. 238: 473-488.

Uhl, G. R., and S. H. Snyder (1976) Regional and subcellular distribution of brain neurotensin. Life Sci. 19: 1827-1832.

Uhl, G. R., R. R. Goodman, and S. H. Snyder (1979) Neurotensincontaining cell bodies, fibers and nerve terminals in the brainstem of the rat: Immunohistochemical mapping. Brain Res. 167: 77-91.

Yamazoe, M., S. Shiosaka, T. Shibasaki, N. Ling, K. Tateishi, E. Hashimura, T. Hamaoka, J. R. Kimmel, H. Matsuo, and M. Tohyama (1984) Distribution of six neuropeptides in the nucleus tractus solitarii of the rat: An immunohistochemical analysis. Neuroscience 13: 1243-1266.

Young, W. S., and M. J. Kuhar (1981) Neurotensin receptor localization by light microscopic autoradiography in rat brain. Brain Res. 206: 273-285.

Young, W. S., J. K. Wamsley, M. A. Zarbin, and M. J. Kuhar (1980) Opioid receptors undergo axonal flow. Science 210: 76-78.

Zarbin, M. A., J. K. Wamsley, R. B. Innis, and M. J. Kuhar (1981) Cholecystokinin receptors: Presence and axonal flow in the rat vagus nerve. Life Sci. 29: 697-705.

Zarbin, M. A., J. K. Wamsley, and M. J. Kuhar (1982) Axonal transport of muscarinic cholinergic receptors in rat vagus nerve: High and low affinity agonist receptors move in opposite directions and differ in nucleotide sensitivity. J. Neurosci. 2: 934-941. 